\title{
Experimental Adaptive Digital Performance Monitoring for Optical DP-QPSK Coherent Receiver
}

Borkowski, Robert; Zhang, Xu; Zibar, Darko; Younce, Richard; Tafur Monroy, Idelfonso

Published in:

Proceedings of the European Conference on Optical Communication (ECOC) 2011

Publication date:

2011

Document Version

Publisher's PDF, also known as Version of record

Link back to DTU Orbit

Citation (APA):

Borkowski, R., Zhang, X., Zibar, D., Younce, R., \& Tafur Monroy, I. (2011). Experimental Adaptive Digital Performance Monitoring for Optical DP-QPSK Coherent Receiver. In Proceedings of the European Conference on Optical Communication (ECOC) 2011 (pp. Tu.3.K.5). Optical Society of America. http://www.ecoc2011.org/

\section{General rights}

Copyright and moral rights for the publications made accessible in the public portal are retained by the authors and/or other copyright owners and it is a condition of accessing publications that users recognise and abide by the legal requirements associated with these rights.

- Users may download and print one copy of any publication from the public portal for the purpose of private study or research.

- You may not further distribute the material or use it for any profit-making activity or commercial gain

- You may freely distribute the URL identifying the publication in the public portal 


\title{
Experimental Adaptive Digital Performance Monitoring for Optical DP-QPSK Coherent Receiver
}

\author{
Robert Borkowski ${ }^{1}$, Xu Zhang ${ }^{1}$, Darko Zibar ${ }^{1}$, Richard Younce ${ }^{2}$, Idelfonso Tafur \\ Monroy $^{1}$ \\ ${ }^{1}$ DTU Fotonik, Department of Photonics Engineering, Technical University of Denmark, Ørsteds Plads, \\ Building 343, DK-2800 Kgs. Lyngby, Denmark \\ ${ }^{2}$ Tellabs, 1415 West Diehl Road, Naperville, IL 60563, USA \\ rbor@fotonik.dtu.dk
}

\begin{abstract}
We report on a successful experimental demonstration of a digital optical performance monitoring (OPM) yielding satisfactory estimation accuracy along with adaptive impairment equalization. No observable penalty is measured when equalizer is driven by monitoring module.
\end{abstract}

OCIS codes: $060.1660,060.2330$.

\section{Introduction}

Coherent digital optical communication is already well established and in commercial use. Nonetheless, a vital part of each communication system is a monitoring subsystem, which is still underdeveloped. Due to increasing bit rates, it is very important to be able to isolate impairments, such as chromatic dispersion (CD), polarization mode dispersion (PMD) or optical signal-to-noise ratio (OSNR), affecting transmitted optical signal and mitigate their influence as much as possible in order to ensure best reception quality and thus minimize the number of received bit errors. Digital signal processing (DSP)-based OPM does not require any additional optical hardware and can be seamlessly combined with digital data coming from the coherent receiver. So far, only computer simulations of blind CD equalization realized in monitoring module preceding timing recovery stage were reported in literature [1-3].

In this paper, for the first time, as to our knowledge, we show that experimental estimation of CD affecting the received signal is feasible in this arrangement and allows for entirely autonomous operation of an equalization-enabled digital coherent receiver. We present that the receiver, without prior knowledge of the channel, can adaptively adjust in order to mitigate signal degradation related to $\mathrm{CD}$.

\section{Blind Chromatic Dispersion Monitoring for Digital Coherent Receiver}

We are considering a dual polarization quadrature phase-shift keying (DP-QPSK) receiver consisting of the optical front end and a DSP part, as shown in Figure 1, which follows structure presented in [2,4]. Two samples per each

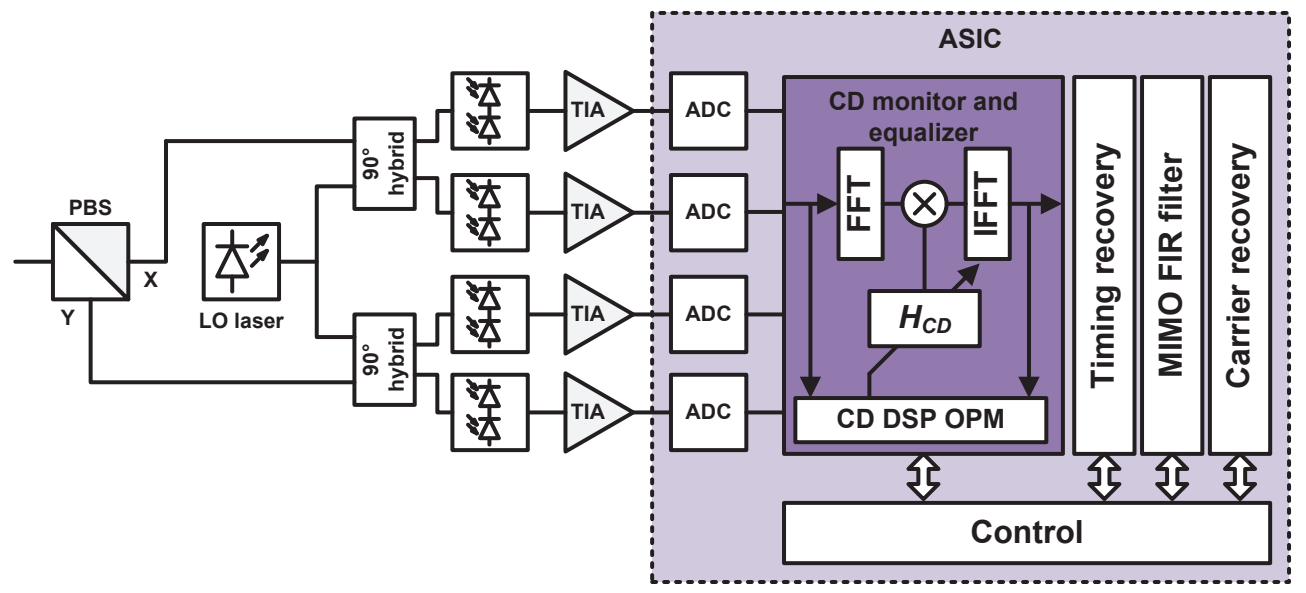

Fig. 1: Typical structure of a digital coherent receiver with CD monitoring and equalization block. Receiver in the figure monitors $\mathrm{CD}$ from time domain samples. 
transmitted symbol are processed by analog-to-digital converters (ADCs). First DSP block, which is of interest to this paper, is used for $\mathrm{CD}$ estimation and adaptive equalization performed with an adjustable transversal $\mathrm{CD}$ equalizer. Following that, timing recovery takes place. A short, 7-tap finite impulse response (FIR) filter is then used for polarization demultiplexing as well as to remove residual impairments. Finally, carrier recovery is performed which results in a stable received constellation.

A generic scanning algorithm is employed for dispersion estimation. CD metric is used to assess if in samples after passing through the equalizer, $\mathrm{CD}$ influence has been removed or not. Range of interest of $C D$ parameter is the lowest and highest value of CD that may affect the incoming signal. The algorithm works as follows. 1) Sweep range of interest of $C D$ parameter, each time setting the transversal equalizer to a candidate transfer function $H_{C D}=$ $\exp \left(j f^{2} \pi \frac{\lambda^{2}}{c} C D\right)$ ( $f$ being clock frequency, $\lambda$, signal wavelength and $c$ the speed of light). As an engineering rule, scanning resolution for a simple maximum or minimum search shall not exceed $300 \mathrm{ps} / \mathrm{nm}$ with a recommended value of $200 \mathrm{ps} / \mathrm{nm}$ for $28 \mathrm{GBd}$ signal, which scales proportionally to symbol rate squared. 2) Equalize the impaired signal with the candidate transfer function. 3) Find the metric of the equalized signal. 4) Repeat steps 2-3 for for each $C D$ value in the swept range. 5) Once metric has been computed for all values of $C D$ parameter in the range of interest, search for the value for which successful CD compensation is indicated by the metric feature.

Four different metrics were used to perform monitoring. First one is based on a constant modulus algorithm (CMA) and was presented in [1]. It penalizes deviation from an expected power. Another, which is a modification to the first one, compares mean power of the uneqalized signal with mean power of post-equalization samples thus judging on whether $\mathrm{CD}$ was compensated. Third method relies on observation of eigenvalues of channel autocorrelation matrix. These techniques work directly with time domain samples. Last method, frequency spectrum autocorrelation [3], is frequency domain-based. Each $\mathrm{CD}$ metric listed above results in a distinctive minimum/maximum when the data signal is correctly compensated for CD.

\section{Experimental setup}

In order to experimentally prove that this monitoring approach is feasible, we focus on a single branch of a polarization multiplexing (PolMux) QPSK transmitter. A pattern generator provides in-phase and quadrature signal at a bit rate of $20 \mathrm{Gbit} / \mathrm{s}$. Resulting optical signal is thus a $40 \mathrm{Gbit} / \mathrm{s}$ single polarization (SP) QPSK. To test monitoring algorithms for different magnitudes of $\mathrm{CD}$ affecting the signal, two cases are investiagated. Firstly, back-to-back transmission (CD-free channel) and $80 \mathrm{~km}$ of standard single-mode fiber (SSMF) with a dispersion coefficient of approximately $16 \mathrm{ps} /(\mathrm{nm} \mathrm{km})$, yielding $1280 \mathrm{ps} / \mathrm{nm} \mathrm{CD}$ in total. The reason for back-to-back trial is to check if the monitoring works correctly even if there is no CD present in the channel. In the next step, optical noise is added to the signal, starting with optical signal-to-noise ratio (OSNR) of $24 \mathrm{~dB}$, down to $12 \mathrm{~dB}$. A preamplifier just before the receiver is used in order to keep power entering a $100 \mathrm{G}$ digital coherent receiver at a constant level of $-10 \mathrm{dBm}$. Local oscillator (LO) is tuned to $1548.88 \mathrm{~nm}$ and signal wavelength is separated by less than $100 \mathrm{MHz}$, both using DFB narrow linewidth lasers (NLLs). Digital storage oscilloscope (DSO) is used to capture the voltage signal after conversion from optical to electrical domain has been performed. Traces recorded by the DSO are then processed offline.

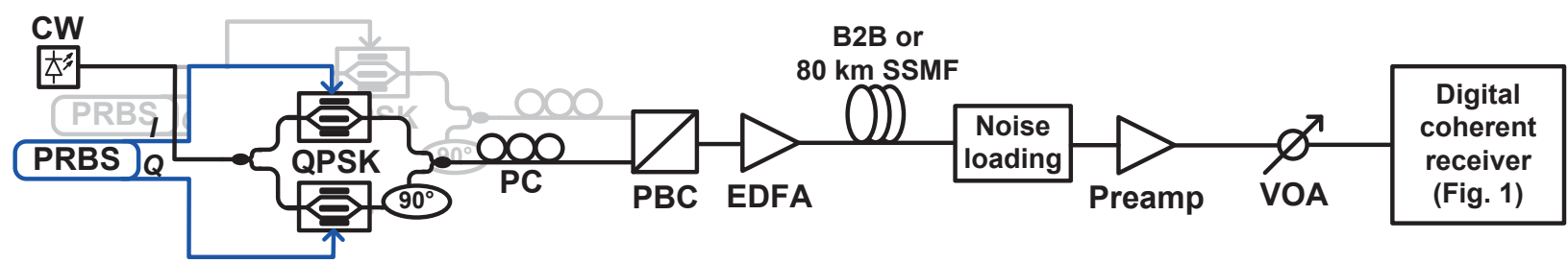

Fig. 2: Experimental setup of the transmission system. CW: continuous wave laser, PRBS: pseudorandom binary sequence generator, PBC: polarization beam combiner, EDFA: erbium-doped fiber amplifier, Preamp: preamplification block, VOA: variable optical attenuator.

\section{Experimental results}

Figure 3 shows bit error rate (BER) curves after demodulation of automatically equalized data, where Preset is a reference line showing performance of the receiver when $\mathrm{CD}$ filter is manually set with an apriori known CD value of either $0 \mathrm{ps} / \mathrm{nm}$ (Figure $3 \mathrm{a}$ ) or $16 \mathrm{ps} /(\mathrm{nm} \mathrm{km}) \cdot 80 \mathrm{~km}=1280 \mathrm{ps} / \mathrm{nm}$ (Figure 3b). Remaining lines show performance of the receiver for different CD metrics as OSNR is varied for both transmission distances. It may be observed that, 


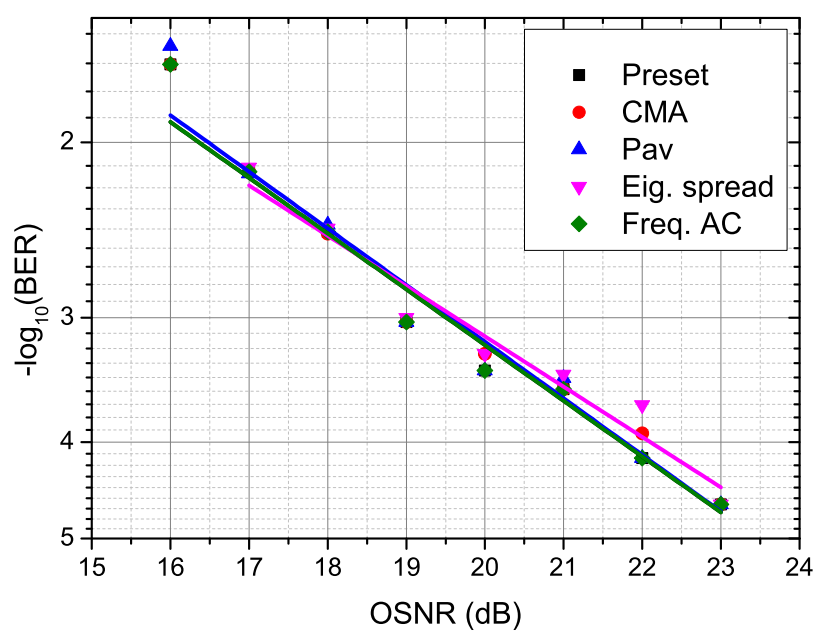

(a) Back-to-back

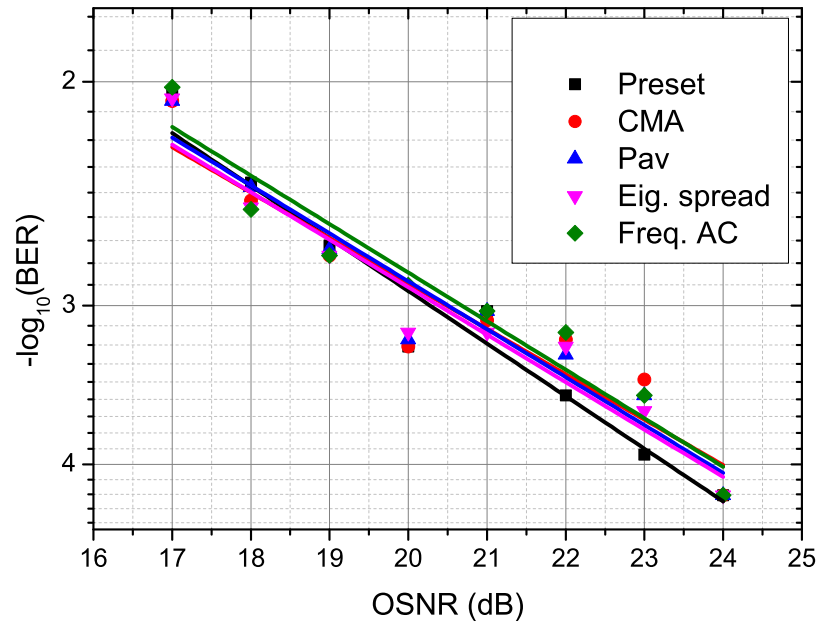

(b) $80 \mathrm{~km} \mathrm{SMF}$

Fig. 3: BER curves for all methods as OSNR varies. Preset: reference line based on apriori known CD filter, CMA: constant modulus algorithm, Pav: mean signal power, Eig. spread: eigenvalue spread, Freq. AC: frequency spectrum autocorrelation

regardless of the $\mathrm{CD}$ distortion present in the channel, lines depart only to a very small extent from the reference Preset line. This proves that CD DSP monitor produces accurate CD estimates allowing for adaptive equalization driven by feedback signal from monitor. It is necessary to point that this proof-of-concept works with SP-QPSK signal. It is, however, scalable to DP-QPSK as CD affects both polarizations equally.

\section{Conclusion}

We experimentally demonstrated the use of DSP OPM algorithms in a CD compensation and estimation module preceding timing recovery stage. This allows for an autonomous operation of a digital coherent receiver in a dispersion noncompensated optical network. To the best of our knowledge this is the first demonstration showing feasibility of this receiver arrangement and algorithms in experimental setting. We found out that four different metrics for assessing dispersion mitigation provide estimations of $\mathrm{CD}$ accurate enough, that no penalty is observed when compared to a $\mathrm{CD}$ filter whose value was fixed prior to the transmission.

\section{Acknowledgements}

We would like to thank Teraxion for providing us PureSpectrum ${ }^{\mathrm{TM}}-\mathrm{NLLs}$ for this experiment. The research leading to these results is partially supported by the CHRON project (Cognitive Heterogeneous Reconfigurable Optical Network) with funding from the European Community's Seventh Framework Programme [FP7/2007-2013] under grant agreement no. 258644.

\section{References}

1. M. Kuschnerov, F. N. Hauske, K. Piyawanno, B. Spinnler, A. Napoli, and B. Lankl, "Adaptive Chromatic Dispersion Equalization for Non-Dispersion Managed Coherent Systems," in Optical Fiber Communication Conference, OSA Technical Digest (CD) (Optical Society of America, 2009), paper OMT1.

2. F. N. Hauske, M. Kuschnerov, B. Spinnler, and B. Lankl, "Optical Performance Monitoring in Digital Coherent Receivers," J. Lightwave Technol. 27, 3623-3631 (2009).

3. F. N. Hauske, C. Xie, Z. P. Zhang, C. Li, L. Li, and Q. Xiong, "Frequency Domain Chromatic Dispersion Estimation," in National Fiber Optic Engineers Conference, OSA Technical Digest (CD) (Optical Society of America, 2010), paper JThA11.

4. Seb J. Savory, "Digital filters for coherent optical receivers," Opt. Express 16, 804-817 (2008). 